\title{
ANALISIS ANTALGIN DALAM JAMU PEGAL LINU YANG DIJUAL DI PASAR BERINGHARJO YOGYAKARTA
}

\author{
Siti Fatimah¹, Muji Rahayu², Debi Firma Indari ${ }^{3}$ \\ ${ }^{1,3}$ Prodi D3 Analis Kesehatan STIKes Guna Bangsa Yogyakarta \\ 2Jurusan Analis Kesehatan Poltekkes Kemenkes Yogyakarta \\ Email : siti fatimah@gunabangsa.ac.id
}

\begin{abstract}
Background: Traditional medicine is an ingredient or ingredients in the form of plant material, animal material, mineral materials, preparation essence (galenic), or mixtures of these materials that have historically been used for treatment, and can be applied according to the prevailing norms in society. Traditional medicine is often chosen as a remedy for health care is herbal, because herbal medicine is a health drink. Chemicals drugs were added by the makers of herbal medicine with the intent may be to increase the efficacy of herbal medicine and herbal medicine provide more instant effect, it is becoming a source of danger herbs. BPOM many find herbs aching pains who defiled chemical medicines like phenylbutazone, methampyrone, diclofenac sodium, piroxicam, paracetamol, prednisone, or dexamethasone. Chemicals a drug it is set in PERMENKES 007 of 2012.
\end{abstract}

Methods: This research is to describe the whether or not of chemicals in the antalgin sold in the Beringharjo traditional market Yogyakarta. The method used to test the lab using thin layer chromatography. Research data presented in terms of percent.

Results: Research is obtained value Rf sample 0.63 until 0.8 one sampel having the value $\mathrm{Rf}$ and fluorescence equal to standard methampyrone. Value Rf standard methampyrone 0,78 and red purple fluorescence.

Conclusion: There are methampyrone in herbal medicine aching pains sold in the Beringharjo traditional market to a presentation positive results as many $8.3 \%$ and negative results $91.7 \%$.

Keywords: Methampyrone, Stiff Rheumatic Pain Herb, Thin Layer Chromatography.

\section{PENDAHULUAN}

Obat tradisional adalah bahan atau ramuan bahan yang berupa bahan tumbuhan, bahan hewan, bahan mineral, sediaan sarian (galenik), atau campuran dari bahan tersebut yang secara turun temurun telah digunakan untuk pengobatan, dan dapat diterapkan sesuai norma yang berlaku di masyarakat (PERMENKES RI Nomor 007 Tahun 2012). Obat Tradisional dilarang mengandung BKO seperti yang diatur dalam PERMENKES nomor 007 tahun 2012 tentang registrasi obat tradisional.
Bahan Kimia Obat yang ditambahkan oleh pembuat jamu untuk menambah khasiat jamu dan memberikan efek jamu yang lebih instan, hal ini menjadi sumber bahaya jamu. Permasalahan Obat Tradisional (OT) mengandung BKO bukan hanya menjadi permasalahan di Indonesia melainkan juga di seluruh dunia. Berdasarkan informasi melalui Post Marketing Alert System (PMAS), World Health Organization (WHO) dan US Food and Drug Adinistration (FDA) sebanyak 30 OT dan suplemen kesehatan (SK) mengandung BKO serta bahan dilarang 
lainnya juga ditemukan di negara-negara ASEAN, Australia, dan Amerika Serikat. Ketiga puluh delapan produk tersebut diduga merupakan produk luar negeri (BPOM, 2015).

Badan POM mengeluarkan peringatan publik pada tanggal 24 Agustus 2015 terkait OT dan Suplemen Kesehatan stamina pria mengandung BKO. Badan POM mengumumkan daftar OT mengandung BKO yang dilarang untuk dikonsumsi masyarakat. Sebanyak 54 OT mengandung BKO dimana 47 diantaranya merupakan OT tanpa nomor izin edar/ilegal. Bahan Kimia Obat yang teridentifikasi dicampur dalam temuan produk OT hingga November 2015 didominasi oleh penghilang rasa sakit, dan antirematik. Badan POM melakukan penarikan terhadap 54 OT mengandung BKO tersebut dari peredaran untuk selanjutnya dilakukan pemusnahan. Pada tahun 2015 telah dilakukan pemusnahan terhadap OT senilai 75,7 miliar rupiah dan bahan baku OT senilai 63,55 miliar rupiah. Sebanyak 7 item hasil temuan OT mengandung BKO yang telah terdaftar, nomor izin edarnya telah dibatalkan dan 115 kasus peredaran OT mengandung BKO berhasil diungkap dan diajukan ke pengadilan sepanjang tahun 2014 sampai tahun 2015 (BPOM, 2015).

Berdasarkan pemeriksaan yang dilakukan Balai Besar POM DIY terhadap $60(20,76 \%)$ pengrajin jamu gendong dan jamu racikan dari 289 sarana yang ada pada tahun 2014. Hasilnya 33,33\% sarana tidak memenuhi ketentuan. Dalam rangka pengawasan mutu obat tradisional yang beredar selama tahun 2014 BBPOM DIY melakukan uji laboratorium terhadap 618 sampel dengan 7905 parameter uji, baik kimia maupun mikrobiologi $(12,79$ parameter/sampel). Hasil dari pengujian terhadap 618 sampel tersebut didapatkan 296 sampel tidak memenuhi syarat parameter kimia maupun mikrobiologi. Sebanyak $66 \quad(10,68 \%)$ sampel dari sampel yang tidak memenuhi standar yang ditemukan mengandung BKO (BBPOM DIY, 2014).

Berdasarkan hasil pengawasan dan pemeriksaan yang dilakukan BPOM jamu pegal linu sering dicemari BKO seperti Fenilbutason, antalgin, diklofenak sodium, piroksikam, parasetamol, prednison, atau deksametason (BPOM, 2013). Jamu pegal linu merupakan jamu yang banyak dikonsumsi oleh para pekerja berat.Jamu pegal linu dikonsumsi untuk mengurangi rasa nyeri, menghilangkan pegal linu, capek, nyeri otot dan tulang, memperlancar peredaran darah, memperkuat daya tahan tubuh, dan menghilangkan sakit seluruh badan. Berdasarkan beberapa kasus tentang BKO dalam jamu pegal linu yang berhasil diungkapkan BPOM, BKO yang paling sering ditemukan adalah antalgin (Handoyo, 2014).

Antalgin (metampiron) adalah derivate metansulfonat dari Amidopirina yang bekerja terhadap susunan saraf pusat yaitu mengurangi sensitivitas reseptor rasa nyeri dan mempengaruhi pusat pengatur suhu tubuh. Tiga efek utama adalah sebagai analgesik, antipiretik dan anti-inflamasi (Binar alkes, 2015).

Kromatografi lapis tipis yaitu pemisahan komponen suatu senyawa dari senyawa lain dimana komponen dari senyawa tersebut akan terdistribusi diantara dua fase yaitu fase diam dan fase gerak serta kepolaran senyawa yang akan diidentifikasi. Komponen yang memiliki interaksi lebih besar terhadap fase diam akan bertahan lebih lama sebaliknya komponen yang memiliki interaksi lebih kecil terhadap fase gerak akan bergerak lebih cepat.Tahapan dalam KLT yang merupakan tahapan analisis dimulai dari penotolan sampel dan standar pada plat KLT sampai pengamatan secara visual di bawah sinar UV $254 \mathrm{~nm}$ untuk melihat bercak dari pemisahan komponen (Healty, 2012).

\section{METODE PENELITIAN}

Penelitian ini merupakan penelitian deskriptif dengan tujuan menggambarkan ada tidaknya antalgin pada sampel jamu pegal linu yang dijual di pasar Beringharjo Yogyakarta. Metode yang digunakan untuk uji laboratorium yaitu dengan KLT. 


\section{ALAT DAN BAHAN PENELITIAN}

Bahan yang digunakan pada penelitian ini yaitu Methanol, asam asetat glasial, etil asetat, serbuk antalgin, dan plat KLT silica gel GF 254. Peralatan yang digunakan pada penelitian ini adalah Satu set alat KLT, tabung mikro kapiler, tabung reaksi, rak tabung reaksi, gelas kimia, pipet ukur, lampu UV, chamber kromatografi, hairdryer, corong, gelas ukur, kertas saring Whatman no 01, neraca, sendok penyu dan kaca alroji.

\section{PROSEDUR PENELITIAN}

a. Pembuatan standar antalgin

Bubuk antalgin ditimbang sebanyak 10 gram dan dilarutkan dalam $5 \mathrm{ml}$ methanol kemudian didiamkan selama 10 menit selanjutnya disaring menggunakan kertas whatman no 1 , kemudian fitrat diuapkan, proses ekstraksi standar dilakukan sebanyak 3 kali.

b. Proses ekstraksi

1) Sampel jamu pegal linu ditimbang sebanyak 2 gram dan dimasukkan ke dalam tabung reaksi.

2) Larutan methanol sebanyak $5 \mathrm{ml}$ ditambahkan ke dalam tabung reaksi yang berisi sampel jamu pegal linu dan didiamkan selama sepuluh menit, kemudian dikocok.

3) Larutan dalam tabung reaksi disaring dengan kertas whatman No1.

4) Filtrat dimasukkan ke dalam gelas kimia.

5) Ekstraksi diulangi sebanyak 3 kali.

6) Filtrat diuapkan.

c. Filtrat siap untuk diteteskan pada plat KLT. Analisis Mengunakan Kromatografi Lapis Tipis

1) Plat KLT , chamber dan bahan yang akan digunakan disiapkan.

2) Eluen dibuat dengan campuran etil asetat dengan asam asetat glasial (24:1) dengan total volume $100 \mathrm{~mL}$ dengan mencampur larutan etil asetat sebanyak $96 \mathrm{ml}$ dan larutan asam asetat glasial sebanyak $4 \mathrm{ml}$ kemudian dimasukkan dalam chamber.

3) Chamber dijenuhkan menggunakan kertas saring, jika kertas saring sudah basah menandakan chamber sudah terjenuhkan oleh pelarut.

4) Sampel dan standar pembanding antalgin ditotolkan dengan tabung mikrokapiler pada plat KLT dengan jarak $1,5 \mathrm{~cm}$ dari bagian bawah plat dan jarak antar noda 1,5 cm biarkan hingga kering.

5) Plat KLT dimasukkan ke dalam chamber dan diamati.

6) Pelarut dibiarkan merambat dengan jarak rambat elusi $8 \mathrm{~cm}$ dari totolan.

7) Setelah mencapai jarak elusi, plat KLT dikeluarkan dan dikeringkan.

8) Kromatogram dilihat di bawah sinar ultraviolet kemudian tandai bercak menggunakan pensil.

9) Nilai faktor retensi (Rf) dihitung.

\section{HASIL DAN PEMBAHASAN}

Penelitian yang berjudul "Analisis Antalgin Dalam Jamu Pegal Linu Yang Dijual Di Pasar Beringharjo Yogyakarta" menggunakan metode KLT. Pertama yang dilakukan dalam identifikasi antalgin dalam jamu pegal linu adalah ekstraksi sampel. Jamu pegal linu ditimbang sebanyak 2 gram dan dimasukkan ke dalam tabung reaksi yang sudah diberi label sesuai dengan kode sampel. Masing-masing sampel jamu pegal linu ditambahkan dengan methanol sebanyak $5 \mathrm{ml}$ dan ditutup menggunakan plastik agar methanol tidak menguap, karena methanol bersifat volatil, selanjutnya didiamkan selama 10 menit.Setelah didiamkan selama 10 menit kemudian dikocok dan disaring menggunakan kertas saring Whatman Nomor 1. Hasil dari penyaringan ditampung dalam gelas kimia yang sudah diberi label sesuai kode sampel.

Pemilihan pelarut yang digunakan untuk ekstraksi sampel berhubungan dengan sifat fisika dan kimia dari komponen yang kita ekstraksi dari sampel.Pelarut yang dipilih adalah methanol karena methanol merupakan 
pelarut yang baik dan dilihat dari kepolarannya methanol lebih polar dari etanol. Fase gerak yang digunakan adalah campuran etil asetat dan asam asetat glasial dengan perbandingan 24:1. Pemilihan fase gerak didasarkan pada sifat fisika dan kimia yang dimiliki antalgin. Selain itu pemilihan fase gerak yang digunakan dilihat dari kepolaran yang dimiliki larutan tersebut karena kepolaran sangat berpengaruh pada nilai Rf.

Proses ekstrasi BKO antalgin dalam jamu pegal linu diulangi sebanyak 3 kali agar BKO antalgin benar-benar terpisah dari komponen sampel. Filtrat yang didapatkan dari hasil ekstraksi diuapkan menggunakan hairdrayer untuk menghilangkan methanol dari filtrat sehingga tidak mengganggu dalam proses analisis. Proses penguapan ini dilakukan sampai filtrat menjadi kental atau pasta, dan filtrat siap ditotolkan pada plat KLTmenggunakan tabung mikro kapiler.

Chamber dijenuhkan dengan cara kertas saring dan dimasukkan kedalam chamber yang sudah diisi eluen, jika eluen sudah naik dan membasahi kertas saring sampai bagian atas menandakan chamber sudah terjenuhkan oleh eluen. Tujuan penjenuhan agar atmosfer dalam chamber penuh dengan uap eluen sehingga pada proses eluasi kecepatan penguapan eluen sama pada semua sisi permukaan plat KLT.

Plat KLT yang sudah ditotolkan filtrat sampel dimasukkan ke dalam chamber yang sudah jenuh, kemudian ditunggu hingga eluen bergerak mencapai garis batas atas plat KLT. Standar yang digunakan pada penelitian ini adalah zat antalgin yang diekstrak dari serbuk antalgin.

Jika nilai Rf sampel sama dengan nilai $\mathrm{Rf}$ standar antalgin dan fluoresensi sampel dan standar juga sama maka sampel dikatakan positif mengandung BKO antalgin. Panjang gelombang sinar UV yang digunakan untuk melihat fluoresensi BKO antalgin pada penelitian ini adalah $254 \mathrm{~nm}$ karena senyawa organik dapat berfluoresensi pada panjang gelombang tersebut dan pada panjang gelombang tersebut yang berfluoresensi adalah plat KLT dan nodanya tampak gelap sehingga fluoresensinya nampak jelas.

Hasil pemeriksaan jamu pegal linu yang mengandung antalgin sebesar $8,3 \%$ dan yang tidak mengandung antalgin adalah $91,7 \%$. Sampel yang positif mengandung antalgin pada penelitian ini sebanyak 1 sampel dari 12 sampel.

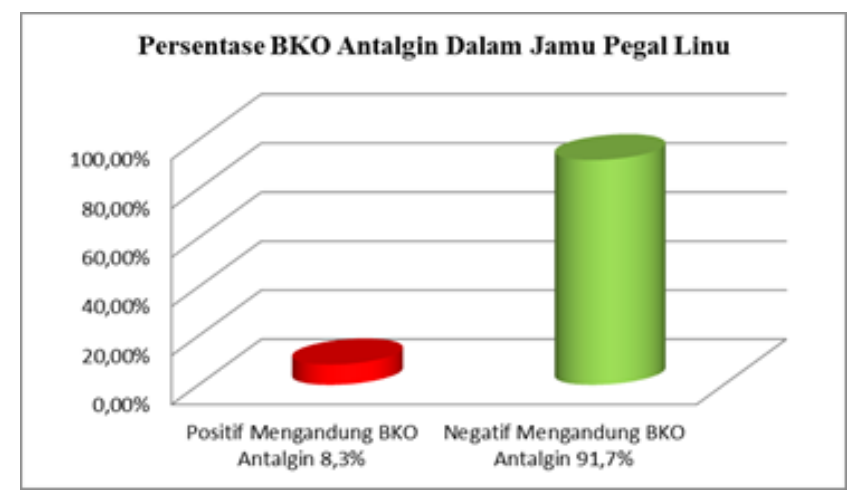

Gambar 1. Persentase BKO Antalgin dalam Jamu Pegal Linu

Jamu pegal linu yang positif mengandung BKO antalgin yaitu jamu pegal linu serbuk yang tidak memiliki kemasan, dijual kiloan, tidak terregistrasi, dan tidak memiliki izin edar, dengan ciriciri tersebut kemungkinan jamu ini merupakan racikan rumah tangga. Jamu tersebut tidak terregistrasi dan tidak memiliki izin karena tidak diuji untuk syarat-syarat kualitas jamu oleh BPOM sebelum dijual di pasaran, sehingga dicurigai dan kemungkinan besar mengandung BKO. Jamu pegal linu yang positif mengandung antalgin dilihat dari nilai $\mathrm{Rf}$, sampel ini memiliki nilai $\mathrm{Rf}$ yang sama dengan standar antalgin yaitu 0,78. Selain nilai Rf juga dilihat dari fluoresensi dibawah sinar UV yang dihasilkan dari komponen sampel ini yaitu merah ungu sama dengan fluoresensi standar antalgin yang juga berfluoresensi merah ungu yang dilihat di bawah sinar UV pada panjang gelombang $254 \mathrm{~nm}$. 


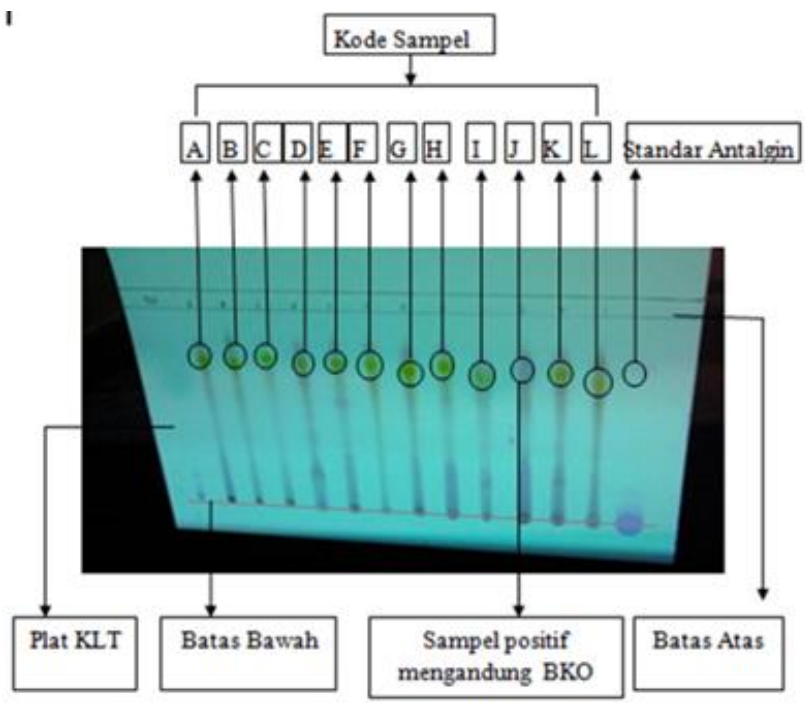

Gambar 2. Kromatogram di Bawah Sinar UV

Sampel yang tidak mengandung BKO antalgin pada penelitian ini sebanyak 11 sampel dari 12 sampel yaitu sebanyak 5 sampel yang berkemasan (sachet), bermerek, terregistrasi, dan memiliki izin edar. Sebanyak 3 sampel berkemasan, bermerek, tetapi tidak terregistrasi dan tidak memiliki izin edar. Sebanyak 3 sampel tidak berkemasan (kiloan), tidak bermerek, tidak terregistrasi dan tidak memiliki izin edar. Sampel yang negatif mengandung antalgin memiliki nilai $R f$ yang berbeda dengan standar antalgin dan fluoresensi di bawah sinar UV juga tidak sama dengan fluoresensi standar antalgin.

Hasil dari penelitian ini jika dibandingkan dengan hasil penelitian yang dilakukan oleh Banureah tahun 2009 dengan judul "Analisis Kandungan Metampiron Pada Jamu Tradisional Yang Beredar Di Kota Medan Tahun 2009". Penelitian Banureah (2009) sejalan dengan penelitian yang dilakukan penulis bahwa pada jamu tradisional ditemukan antalgin, namun hasil penelitian Banureah (2009) menunjukkan 100\% sampel jamu tradisional yang diperiksa positif mengandung metampiron, hasil positif pada penelitian Banureah (2009) jauh lebih besar dibandingkan hasil positif pada penelitian penulis yang hanya sebesar $8,3 \%$. Penelitian ini dilaksanakan pada tahun yang berbeda maka tidak menutup kemungkinan penambahan antalgin atau metampiron pada obat tradisional yang beredar di kota Medan pada tahun 2016 lebih sedikit dibandingkan tahun 2009 atau bahkan jauh lebih banyak dibandingkan tahun 2009. Penelitian Banureah (2009) yang diuji bukan hanya jamu pegal linu tetapi obat tradisional yang beredar di kota Medan sehingga tidak menutup kemungkinan di pasar Beringharjo Yogyakarta juga terdapat kandungan metampiron/antalgin pada obat tradisional selain jamu pegal linu, misalnya seperti jamu asam urat.

Antalgin ini ditambahkan dalam jamu pegal linu oleh produsen jamu untuk meningkatkan khasiat jamu dan memberikan efek instan sehinga lebih diminati konsumen sehingga meningkatkan keuntungan produsen jamu itu sendiri, tanpa mengetahui dan melihat bahaya BKO jika ditambahkan ke dalam jamu. Antalgin sering ditambahkan ke dalam jamu pegal linu karena antalgin merupakan obat generik yang murah dan mudah didapatkan.

Bahan kimia obat jika masuk ke dalam tubuh akan melalui beberapa tahapan, secara umum proses yang dialami obat dalam tubuh yaitu transfor obat, absorpsi, distribusi, metabolisme dan ekskresi. Proses-proses tersebut tentunya menggunakan organ-organ tubuh seperti jantung, hati, dan ginjal (Nugroho, 2012).Jika BKO ditambahkan ke dalam jamu maka kadar BKO tidak sesuai dengan resep dokter dan dikonsumsi dalam jangka waktu yang panjang, hal ini akan mengakibatkan penurunan fungsi dan kerusakan organorgan yang digunakan untuk proses obat di dalam tubuh.

Antalgin tidak termasuk bahan kimia obat yang berbahaya namun berbahaya jika keberadaan antalgin di dalam jamu karena dengan kadar yang tidak diketahui dan waktu mengkonsumsinya dalam jangka waktu yang panjang. Antalgin jika dikonsumsi secara terus-menerus juga memiliki efek samping yaitu gangguan sistem cerna seperti mual, pendarahan lambung, rasa terbakar, serta gangguan 
sistem saraf, gangguan darah, gangguan ginjal, syok, bahkan kematian.

\section{KESIMPULAN DAN SARAN}

\section{A. KESIMPULAN}

Berdasarkan hasil penelitian "Analisis Antalgin Dalam Jamu Pegal Linu Yang Dijual Di Pasar Beringharjo Yogyakarta" yang telah dilakukan dapat diambil kesimpulan yaitu $8,3 \%$ sampel jamu pegal linu yang positif mengandung antalgin.

\section{B. SARAN}

Bagi pembaca yang tertarik melanjutkan penelitian ini perlu dilakukan penelitian lebih lanjut untuk mengetahui kandungan BKO lain seperti parasetamol dan jenis analgesik lainnya.

\section{DAFTAR PUSTAKA}

Badan Pengawasan Obat dan Makanan.2013.Bahaya Bahan Kimia Obat (BKO) Yang Dibubuhkan Kedalam Obat Tradisional (Jamu), Jakarta.

Badan Pengawasan Obat dan Makanan. 2015. Bahan Kimia Obat Dalam Obat Tradisional dan Suplemen Kesehatan. Siaran pers, Jakarta.
Balai Besar Pengawasan Obat dan Makanan Daerah Istimewa Yogyakarta.2014.Laporan Tahunan 2014, Yogyakarta.

Banureah EM. 2009. Analisis Kandungan Metampiron Pada Jamu Tradisional Yang Beredar Di Kota Medan. Skripsi. Fakultas Kesehatan Masyarakat Universitas Sumatra Utara.

Binar Alkes. 2015. Hak Pasien Memilih Obat Generik. Departemen Kesehatan RI, Jakarta: 26
Handoyo K. 2014. Jamu Sakti Mengobati Berbagai Penyakit. Dunia Sehat, Jakarta Timur: 13-14, 67-68, 78.

Healty.2012. Percobaan Pemanfaatan Kromatografi Lapis Tipis Dalam Analisis Identifikasi Jamu Palsu.Ghalib, Jakarta: 37-38.

Nugroho AE. 2012. Prinsip Aksi \& Nasib Obat Dalam Tubuh.Pustaka Pelajar, Yogyakarta: 73-106.

Peraturan Menteri Kesehatan RI No, 007 Tahun 2012 Tentang Registrasi Obat Tradisional, Departemen Kesehatan RI, Jakarta. 